\title{
Construction and Safety of Data Communication Network of Electric Power Information System
}

\author{
JINXIANG CHENG ${ }^{1}$, XIAOBEI WANG ${ }^{1}$, JINZHI GUO ${ }^{1}$, PENG CHEN ${ }^{1}$, \\ CHANGGAO $\mathrm{LI}^{1}$
}

1State Grid Hubei Electric Power Company Huanglongtan Hydropower Plant, Shiyan 442000, China

\begin{abstract}
The power industry is the foundation and pillar industry of the country, and it is also an important industry related to the people's livelihood. After the information construction in recent years, the power plant has built the information system of power information data communication network. The safe and reliable operation of the information system, a direct impact on power production work, information system security has been from a single IT system security into an important part of electricity safety production.
\end{abstract}

Keywords: Data Communication Network, Electric Power, information system security

\section{BACKGROUND}

In recent years, with the continuous development of information technology, in order to meet the power system security, stability and efficient production needs and power grid companies to market demand, power plant integrated data communication network has experienced a rapid development process. In order to solve the problem of security and security of large data transmission in the integrated data communication network, the security protection of special business, real-time business and high security business is realized. The research and construction of integrated data communication network security system of power plant is realized, Data network large data transmission security and efficient management, to achieve a qualitative leap in network security, the following data on the power plant communications network security system research and construction of the content described in detail.

With the development of the power industry, the scale of the power grid is gradually expanding and the structure is becoming more and more complicated. In order to ensure the safe and stable operation of the power grid, the power transmission and distribution system of the power system is required to have a very high level of automation. As a guarantee of power grid operation, control and management of information transmission Of the power communication network in the reliability and safety of the island level requirements. The high dependence of power grid on power communication network makes the research of power communication network become an important aspect of power system security. 
Power communication network as a power system of the communications network, carrying all the power system communications business, different business functions in the power system and the role of different security and reliability, and so have different needs. The uniqueness and specificity of these services, in the reliability and security requirements of the differences, leading to power communication network in the risk of research has a more obvious industry characteristics. For different power services for reliability, stability, real-time and security and other aspects of the different needs of the power network using different network technology to carry a different business.

\section{BASIC CONCEPT OF POWER COMMUNICATION NETWORK}

The power communication network is a private network that is connected by dedicated power communication equipment and carries various power communication services. The communication equipment in the power communication network is similar and different from the communication equipment of the ordinary network. Their purpose is to complete the information transmission. The difference lies in the particularity of the power industry. The power communication network has many characteristics such as communication resources, The reliability of the power communication network is higher. From the definition of power communication network can be seen, the power communication network is mainly composed of two aspects of power communication equipment and communication services. Power communication equipment is composed of power communication network and services in the power grid operation and management of communication facilities, including transmission network equipment, business network equipment, support network equipment and other four categories. Power communication network for the power grid scheduling, production operation, management of the communications business. The grid communication service is divided into two types: grid communication service and grid management communication service.

\section{CHINA'S INFORMATION AND COMMUNICATION NETWORK SECURITY STATUS}

With the continuous deepening of information technology and power companies rely on the continuous strengthening of information networks, information security and key technologies and its combination with the power of information network research is very important. China's power industry in the information security has been a certain amount of investment, most of the power companies to take the necessary security measures, such as identity authentication, firewall, anti-virus system and intrusion detection system. In general, most of the existing systems are point and local protective measures, can not achieve a high level of defense. Therefore, the structure of power information system to follow the development of information technology for the corresponding changes in the establishment of defense systems in depth defense in order to effectively resist all kinds of attacks, improve the power industry information system security.

\section{POWER NETWORK STRUCTURE}

Power communication network is currently focusing on the development of optical communication, and based on optical communication technology to build data network, voice switching network, clock synchronization network, video conferencing systems, and other power grid-specific power line carrier communications, and the use 
of satellite communications, wireless communications as emergency communications the way. At present the system has basically covered the network, provincial, prefecture-level units, and continue to expand to a level unit.

The application of ordinary communication network in the power grid mainly in rural power network information, distribution network automation and emergency communications, etc., through the rental operator circuit resources to achieve rural power information construction, rental GPRS / CDMA wireless communication resources to solve the distribution monitoring, Customer control, low-voltage collection, etc. with the use of electrical communication problems, rental fiber, circuit resources as a real-time control of the power grid standby channel. However, because the public network communication is mainly for the social users, not for the power industry industrial control and information security to provide the necessary technical services, the current use of network instability, demand and failure to deal with some technical and management issues, The status of power communication network construction, that is, the underlying transmission based on technology, power network multi-level construction, including power plant communication network and regional communication network.

\section{POWER PLANT COMMUNICATION NETWORK NETWORK ARCHITECTURE}

Power plant communication network using multi-layer architecture, including bearing plane, business network plane, business plane and so on. Business plane mainly includes a variety of voice, data, multimedia and other production and management business. Business network plane, including scheduling data network, integrated data network, scheduling switching network, administrative switching network. The data network mainly carries the non-control data service. The integrated data network mainly carries the production information management business, the dispatch exchange network mainly carries the dispatching telephone service, the administrative exchange network carries the administrative telephone service and the related value-added service.

Technology to build the transmission network, mainly carrying a variety of control services and business networks; scheduling data network is mainly used for carrying the scheduling data services and relay distribution network automation business, integrated data network using fiber directly connected and construction methods, mainly for carrying production management Information services and video conferencing, softswitch and other networks. The administrative switching network is constructed by softswitch technology, which is carried on the integrated data network. The scheduling switching network adopts the program-controlled switching technology construction, which mainly carries the dispatching telephone.

\section{ANALYSIS OF THE IMPORTANCE OF POWER COMMUNICATION BUSINESS}

With the increasing scale of power grid, the improvement of power grid complexity, as the power grid support network of power communication network business has diversified, covering a wide range of features, covering transmission, substation, power generation, scheduling and other power grid links. According to the traditional business division, power communication business includes four categories: voice business, data services, video services and multimedia services. Each type of 
communication services in the power system production and operation of different functions, the reliability of communication, security, real-time requirements are also different.

\section{COMMUNICATION NETWORK SECURITY DEFINITION \\ 7.1 INFORMATION SECURITY}

Power communication network as the main carrier of information transmission, its security is one of the key issues in information security. To clarify the meaning of communication network security, we must first define the information security, information security usually refers to the information in the collection, transmission, storage and application process, such as integrity, confidentiality, availability, controllability and non-repudiation. In order to achieve the above information security, the need to establish information security management mechanism, the development of information security strategy; the development of information security evaluation standards to assess and divide the security level; use of security management, products and networks to protect the collection, transmission, storage and application of confidentiality Integrity, availability, controllability, and non-repudiation; the application of detection mechanisms to learn about the current security state; through failure and disaster recovery mechanisms to solve the problems. Information network security refers to the reliability and survivability of the communication network itself (bearer network and service network) in the process of transmitting the service provided by the network; the availability and controllability of the network service; the integrity of the information in the information transmission process Sex, confidentiality and non-repudiation.

\subsection{COMMUNICATION NETWORK SECURITY}

Communication network security usually includes bearer network and service network security, network service security and information transmission security. Communication network security does not involve ideological security. Bearer network and service network security include network reliability and survivability. Network reliability and survivability rely on environmental security, physical security, node security, link security, topology security, system security and other aspects to protect. Here bearer network and business network is to have their own nodes, links, topology and control of the network, such as transmission network, Internet, telephone network, mobile communication network, support network and other telecommunications networks.

Network service security includes service availability and service controllability. Service availability is related to bearer network and service network reliability and maintenance capabilities. Service control depends on service access security, and services to prevent denial, service anti-attack and other aspects to protect. Services can be provided by the network voice services, VPN services, Internet services.

Information security includes information integrity, confidentiality and nonrepudiation. Information integrity can rely on packet authentication mechanism to protect; information confidentiality can rely on encryption mechanisms and key distribution to protect; information can not rely on digital signatures and other technical support.In the process of building information security system, the following points need to focus on.

First, fully understand the needs of their own enterprises, the scope and objectives of system construction. 
Second, a comprehensive grasp of the status of information under the jurisdiction of enterprises, and according to the standard necessary assignment, and carry out risk assessment on a regular basis.

Third, the full understanding of the importance of the establishment of information security system management department, only a strong management support and cross-sectoral teamwork in order to truly implement the system management. Fourth, we must continue to carry out the system of publicity, so that all employees can really realize that the information security system is a continuous process of recycling, there is no immutable management, there is no immutable technical means. Only in the joint efforts of all staff, so that information security throughout the production and operation of all aspects of the full attention to the above four aspects of the problem, in order to build a good information security system, run well in order to continuously improve the level of enterprise information security management.

\section{CONCLUSION}

The smart grid combines the power system with the information communication system to realize the highly integrated integration of the power flow, the information flow and the business flow. The security of power communication network has become an important guarantee for the secure communication information platform of strong smart grid. The traditional characteristics of power communication network performance for the day without interruption, high reliability, special closed, effectively put an end to a large number of external risks. At the same time, data communication network technology is gradually penetrating to the transmission, access, exchange, signaling, support, mobile, billing, management and other networks. However, the data communication network technology for the power communication network to reduce the cost of hardware and software, bringing the development of operation and maintenance services convenience, but also the introduction of additional security risks. Therefore, the construction of power communication network security system architecture to protect the power of data communication network to facilitate the process of avoiding disadvantages, the power communication network risk control within the acceptable range, is necessary.

\section{REFERENCES}

1. Zhang Yongmei. Computer communication network security overview. China Science and Technology Information, 2006.

2. Yang Hua. Research and Application of Network Security Technology. Computer and Network, 2008.

3. Feng Miao. Network security technology. Science and technology information, 2008.

4. Gao will students. Research on Reliability of Power Communication Network. North China Electric Power University, 2009.

5. Liu Ming, He Guangyu Petrochemicals CSA Project Introduction Power System Automation, 2006

6. Yang Xiaoping. Research on Reliability Evaluation Index of Complex Network. Beijing University of Information Science and Technology, 2010.

7. Miao Xin, Zhang Kai, Tian Shiming, etc. Support the smart grid information and communication system. Power grid technology, 2009,33 (17).

8. Xing Qinzhong .ATM communication network. Beijing: People's Posts and Telecommunications Press, 1998. 